\title{
ASSESSMENT OF REFERENCE HEIGHT MODELS ON QUALITY OF TANDEM-X DEM
}

\author{
S. Mirzaee ${ }^{\text {a, } *}$, M. Motagh ${ }^{\text {a, b }}$, H. Arefi ${ }^{\text {a }}$ \\ ${ }^{a}$ University of Tehran, Dept. of Surveying and Geomatics Eng., Tehran, Iran - (saramirzaee, hossein.arefi)@ut.ac.ir \\ ${ }^{\mathrm{b}}$ GFZ German Research Centre for Geosciences, Section of Remote Sensing, 14473, Potsdam, Germany - motagh@gfz-potsdam.de
}

KEY WORDS: DEM, Assessment, TanDEM-X, InSAR, Reference Height Model

\begin{abstract}
:
The aim of this study is to investigate the effect of various Global Digital Elevation Models (GDEMs) in producing high-resolution topography model using TanDEM-X (TDX) Coregistered Single Look Slant Range Complex (CoSSC) images. We selected an image acquired on Jun $12^{\text {th }}, 2012$ over Doroud region in Lorestan, west of Iran and used 4 external digital elevation models in our processing including DLR/ASI X-SAR DEM (SRTM-X, 30m resolution), ASTER GDEM Version 2 (ASTER-GDEMV2, 30m resolution), NASA SRTM Version 4 (SRTM-V4, 90m resolution), and a local photogrammetry-based DEM prepared by National Cartographic Center (NCC DEM, 10m resolution) of Iran. InSAR procedure for DEM generation was repeated four times with each of the four external height references. The quality of each external DEM was initially assessed using ICESat filtered points. Then, the quality of, each TDX-based DEM was assessed using the more precise external DEM selected in the previous step. Results showed that both local (NCC) DEM and SRTM X-band performed the best (RMSE $<9 \mathrm{~m}$ ) for TDX-DEM generation. In contrast, ASTER GDEM v2 and SRTM C-band v4 showed poorer quality.
\end{abstract}

\section{INTRODUCTION}

The increasing demand for a precise Digital Elevation Model (DEM) in various applications such as agricultural, navigation, flood management, and defense needs a careful attention in DEM production procedures. One of the best ways to produce DEM is to use high-resolution radar images by implementing InSAR techniques. The most advantage of this method is that it is independent from atmosphere, cloud contamination and sun angle as compared to optical images (Jacobsen, 2004).

One of the most important steps in producing DEM using radar data is the height reference model that is used in interferometric processing to remove long-wavelength topographic phase component from differential interferograms before phase unwrapping. This step helps improve phase unwrapping quality especially in regions with steep slopes and also improve the absolute precision of the final DEM (Chunxia and Linlin, 2005). Usually free global digital elevation models such as ASTER GDEM and SRTM with spatial resolutions of 30 and 90 meters, respectively, are used for this purpose. DEM accuracy highly depends on various parameters including topographic characteristics of the area and therefore the accuracy of global DEMs may vary in different locations (Athmania and Achour, 2014; Gupta et al., 2014; Kolecka and Kozak, 2013; Satgé et al., 2015).

TanDEM-X (TDX) is the first space-born bistatic InSAR sensor that has solved the temporal decorrelation problem of repeat pass sensors. The main purpose of launching TDX was to produce a high precision global DEM with the standards of HRTI-3 (Huber et al., 2009; Krieger et al., 2007). In this study, the effect of various global digital elevation models in producing high-resolution DEMs using TanDEM-X
Coregistered Single Look Slant Range Complex (CoSSC) images is investigated.

In the following sections the assessment procedure and results will be declared.

\section{STUDY AREA AND TANDEM-X DATA}

In this research we used a TanDEM-X Coregistered Single Look Slant Range Complex (CoSSC) image in bistatic mode with the following characteristics acquired on Jun $12^{\text {th }} 2012$ over Doroud region in Lorestan, west of Iran.

\begin{tabular}{ccccc}
\hline $\begin{array}{c}\text { Date of } \\
\text { acquisition }\end{array}$ & $\begin{array}{c}\text { Inc. } \\
\text { angle }\end{array}$ & Pass & $\begin{array}{c}\text { Baseline } \\
(\mathrm{m})\end{array}$ & HoA \\
\hline $12-06-2012$ & 22 & Desc. & 262.34 & 11.87 \\
\hline
\end{tabular}

Table 1: TanDEM-X image characteristics

The study area is located in a mountainous region with a plain in the middle part which is under agricultural cultivations. The shaded relief image is shown in Fig. 1.

\section{METHODOLOGY}

The main objective of this paper is to assess the quality of TanDEM-X InSAR DEM when different height references are used to for long-wavelength topographic phase removal. 4 external digital elevation models were used in our processing including DLR/ASI X-SAR DEM (SRTM-X, 30m resolution),

* Corresponding author 
ASTER GDEM Version 2 (ASTER-GDEMV2, 30m resolution), NASA SRTM Version 4 (SRTM-V4, 90m resolution), and a local photogrammetry-based DEM prepared by National Cartographic Center (NCC DEM, 10m resolution) of Iran.

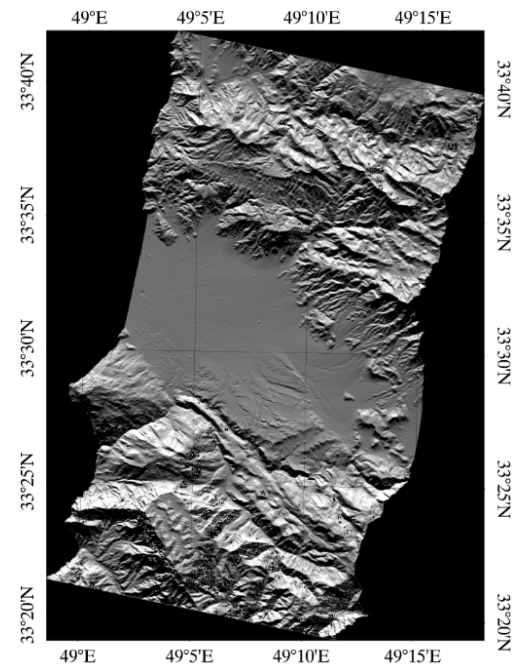

Figure 1: Shaded relief map of TanDEM-X DEM

For the quality assessment, we used ICESat laser altimetry data which are taken with $70 \mathrm{~m}$ diameter footprint, $170 \mathrm{~m}$ along track interval and 5 to $30 \mathrm{~km}$ across track interval in different latitudes ("NASA/ICESat," n.d.). They have $3.7 \mathrm{~m}$ horizontal geolocation accuracy and less than $1 \mathrm{~m}$ vertical accuracy, so they are appropriate for accuracy assessment of large areas. The location of ICESat filtered points on ASTER GDEM v2 and TDX is shown in Fig. 2. All the DEMs are resized to $30 \mathrm{~m}$ pixel size by cubic interpolation. ICESat data are filtered using criteria in Table 2 because of the presence of the systematic errors (Huber et al., 2009).

\begin{tabular}{|l|l|l|l|l|}
\hline ICESat & Std $<7 \mathrm{~m}$ & Width $<25 \mathrm{~m}$ & Energy $<10$ fJ & Peaks $<6$ \\
\hline
\end{tabular}

Table 2: Criteria used for ICESat data filtering

After filtering original ICESat data, we obtained 635 data points in our study area. However, as the ICESat points were not covering all the area covered by TDX image according to Fig. 2 , they could not be used for a complete accuracy assessment of InSAR DEMs. Accordingly, after pre-analysis of external DEMs, each InSAR DEM was assessed again using the more precise external DEM selected in the first step.

The statistical parameters used for assessment include median absolute deviation (MAD) (Leys et al., 2013), standard deviation (STD), root mean square error (RMSE) and NIMA LE90 (Gupta et al., 2014). NIMA LE90 is an overall estimate of the DEM accuracy which assumes the observations have normal distribution and it describes a $90 \%$ confidence interval of the DEM accuracy.

\section{RESULTS AND DISCUSSION}

The four statistical parameters including MAD, STD, RMSE and NIMA LE90 are calculated for the pixels coinciding ICESat points and the results are shown in Figure 3.

In the initial assessment using ICESat points both local (NCC) DEM and SRTM X-band performed the best (RMSE $<9 \mathrm{~m})$. In contrast, ASTER GDEM v2 and SRTM C-band v4 showed poorer quality as it is shown in Figure 3.

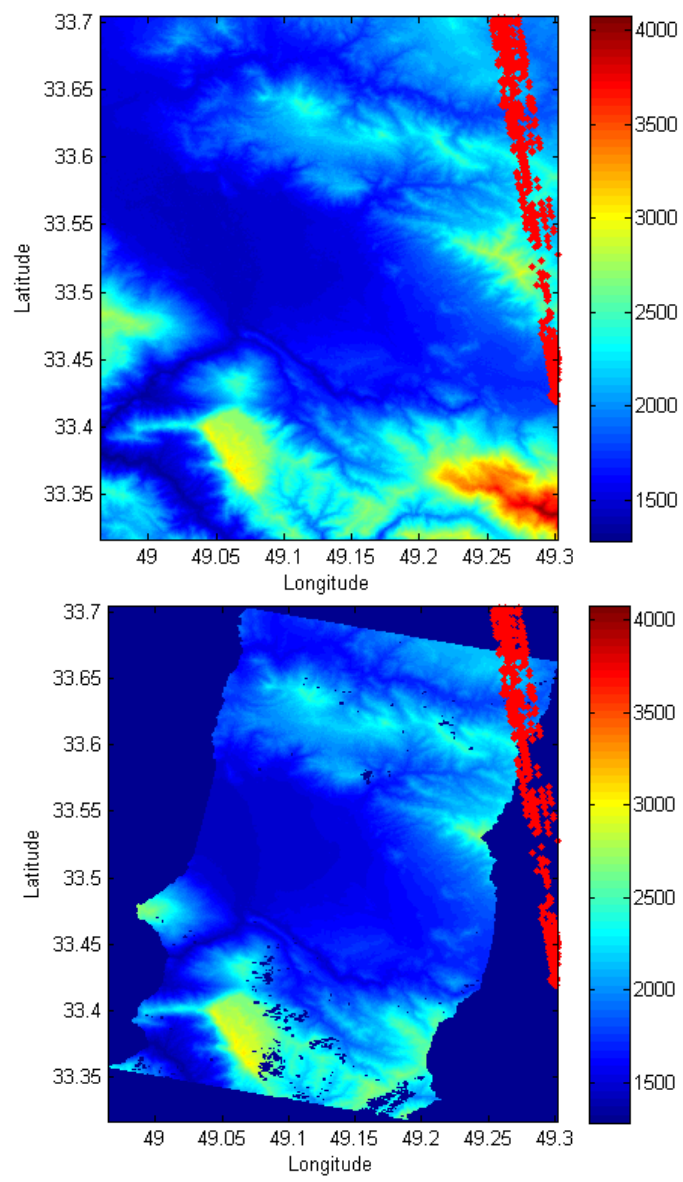

Figure 2: Location of ICESat data (red points) on GDEM v2 (on the top) and TDX (on the bottom)

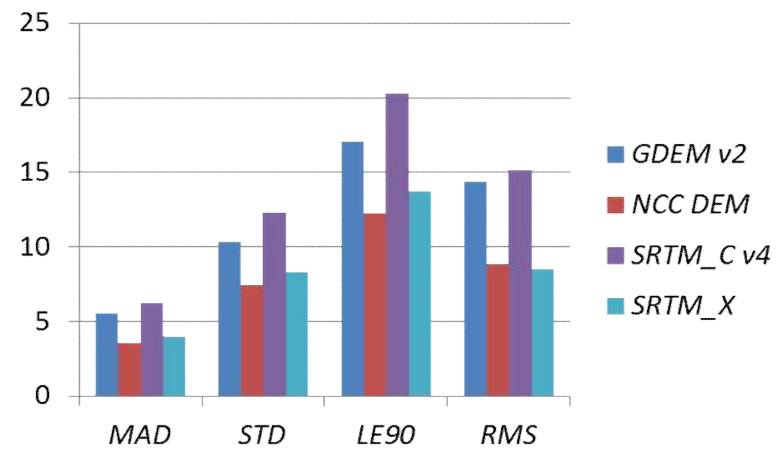

Figure 3: Accuracy assessment of reference height models with ICESat data 
It is assumed that this behavior also exists in the TDX DEMs generated with each of these height references. Therefore the procedure was repeated for TDX DEMs. According to Figure 4 and Table 3, the same results obtained when assessing TDX DEM products generated with each of these height references.

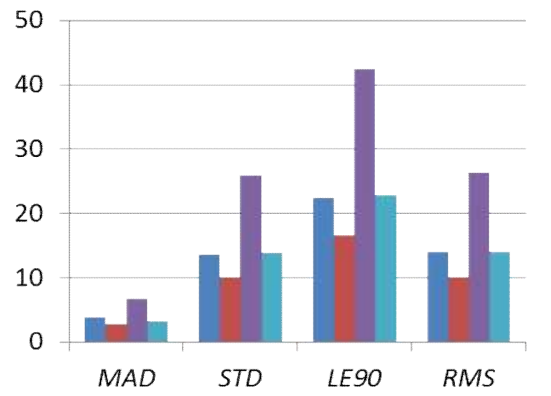

- TDX with GDEM v2

TDX with NCC DEM

- TDX with SRTM_CV4

IDX with SRTM_X

Figure 4: Accuracy assessment of TDX DEM products generated with different height references according to NCC DEM

\begin{tabular}{|c|c|c|c|c|}
\hline & $\begin{array}{l}\text { MAD } \\
\text { (m) }\end{array}$ & $\begin{array}{l}\text { STD } \\
(\mathrm{m})\end{array}$ & $\begin{array}{c}\text { LE90 } \\
(\mathrm{m})\end{array}$ & $\begin{array}{c}\text { RMS } \\
(\mathbf{m})\end{array}$ \\
\hline $\begin{array}{l}\text { TDX with } \\
\text { GDEM v2 }\end{array}$ & 8.62 & 11.43 & 18.81 & 13.23 \\
\hline $\begin{array}{l}\text { TDX with } \\
\text { NCC DEM }\end{array}$ & 6.92 & 10.75 & 17.69 & 10.77 \\
\hline $\begin{array}{l}\text { TDX with } \\
\text { SRTM C v4 }\end{array}$ & 21.79 & 27.36 & 45.04 & 45.98 \\
\hline $\begin{array}{l}\text { TDX with } \\
\text { SRTM X }\end{array}$ & 10.39 & 14.08 & 23.17 & 15.49 \\
\hline
\end{tabular}

Table 3: Statistical parameters calculated for TanDEM-X DEMs

Furthermore, histograms of height differences between each TDX DEM product and NCC height model are shown in Figure 5. The adaption quality to the reference height model is clearly depicted, especially for the SRTM v4 DEM which has obviously skewness with large values of standard deviation.

The sources of systematic errors might change from one sensors type to another one. In the optical DEMs, e.g. ASTER GDEM $\mathrm{v} 2$, presence of clouds, the number of stereo images, and the existence of negative bias cause to reduce the final DEM Accuracy (Arefi and Reinartz, 2011).

In Radar Imaging systems, the factors like incidence angle and baseline which result in different height of ambiguities can have different effects on the final InSAR DEM (Chunxia and Linlin, 2005). According to the assessment which is reported by Kolecka and Kozak in 2013, the land covers specially the vegetation and forest covers decreases the precision up to 10 meters. Other main error sources in C band DEMs are the void values distribution and the steep slopes For X band DEMs the incidence angle and azimuth of the radar beam geometry play a key role in improving the quality of DEM (Kolecka and Kozak, 2013).

In our experiment we find that, although the use of an external height reference model helps effectively in phase unwrapping step of an InSAR DEM generation, a careful consideration should be done on the selection of this reference DEM. We find that the selection of the external DEM may affect the accuracy by more than $10 \mathrm{~m}$ with RMSE increasing from $\sim 10 \mathrm{~m}$ in TDX, corresponding to photogrammetry-based DEM, to $27 \mathrm{~m}$, corresponding to SRTM C band $\mathrm{v} 4$.
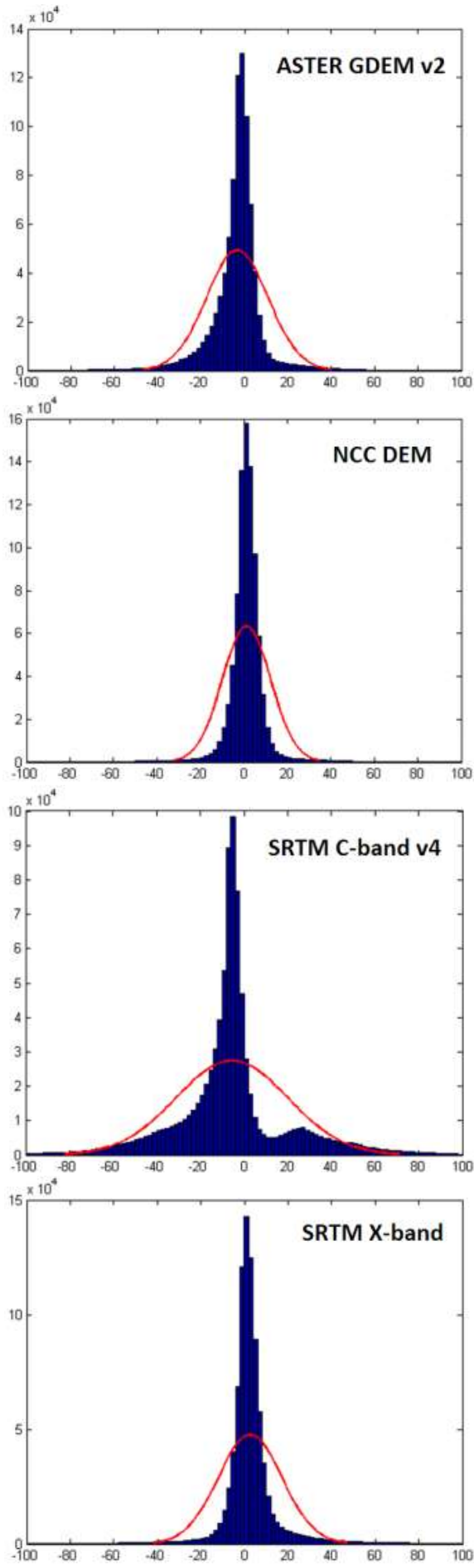

Figure 5: Histogram of differences between TDX DEM products and NCC DEM 
The International Archives of the Photogrammetry, Remote Sensing and Spatial Information Sciences, Volume XL-1/W5, 2015 International Conference on Sensors \& Models in Remote Sensing \& Photogrammetry, 23-25 Nov 2015, Kish Island, Iran

\section{CONCLUSION}

The aim of this paper was to assess the quality of TanDEM-X DEM when different external height references were used in the long-wavelength topographic phase removal step of DEM generation. The results showed that the quality of external DEM highly affects the final DEM quality. In our assessment using different global DEMs for an area west of Iran we found that both local photogrammetry-based DEM and SRTM X-band had the best performance. In contrast, ASTER GDEM v2 and SRTM C-band v4 showed poorer quality in this area. The quality of the final high-resolution TDX DEM could be deteriorated by more than 2 times depending on the external DEM used for processing.

\section{ACKNOWLEDGEMENTS}

The Authors would like to thank the German Aerospace Center (DLR) for providing SAR data under the research proposal XTI LAND0505, and also Iran national cartographic center for providing local DEM.

\section{REFERENCES}

Arefi, H., Reinartz, P., 2011. Accuracy Enhancement of ASTER Global Digital Elevation Models Using ICESat Data. Remote Sens. 3, 1323-1343. doi:10.3390/rs3071323

Athmania, D., Achour, H., 2014. External Validation of the ASTER GDEM2, GMTED2010 and CGIAR-CSI- SRTM v4.1 Free Access Digital Elevation Models (DEMs) in Tunisia and Algeria. Remote Sens. 6, 4600-4620. doi:10.3390/rs6054600

Chunxia, Z., Linlin, G., 2005. A case study of using external DEM in InSAR DEM generation 8, 0-4. doi:10095020(2005)01-014-05

Gupta, R.D., Singh, M.K., Snehmani, S., Ganju, A., 2014. Validation of SRTM X Band DEM over Himalayan Mountain. ISPRS - Int. Arch. Photogramm. Remote Sens. Spat. Inf. Sci. XL-4, 71-74.

doi:10.5194/isprsarchives-XL-4-71-2014

Huber, M., Wessel, B., Kosmann, D., Felbier, A., Schwieger, V., Habermeyer, M., Wendleder, A., Roth, A., 2009. Ensuring globally the TanDEM-X height accuracy: Analysis of the reference data sets ICESat, SRTM and KGPS-tracks, in: International Geoscience and Remote Sensing Symposium (IGARSS). doi:10.1109/IGARSS.2009.5418204

Jacobsen, K., 2004. DEM generation from satellite data. Remote Sens. Transit. 513-525.

Kolecka, N., Kozak, J., 2013. Assessment of the Accuracy of SRTM C- and X-Band High Mountain Elevation Data: a Case Study of the Polish Tatra Mountains. Pure Appl. Geophys. 171, 897-912. doi:10.1007/s00024-013-06955

Krieger, G., Moreira, A., Fiedler, H., Hajnsek, I., Werner, M., Younis, M., Zink, M., 2007. TanDEM-X: A satellite formation for high-resolution SAR interferometry, in:
IEEE Transactions on Geoscience and Remote Sensing. pp. 3317-3340. doi:10.1109/TGRS.2007.900693

Leys, C., Ley, C., Klein, O., Bernard, P., Licata, L., 2013. Detecting outliers: Do not use standard deviation around the mean, use absolute deviation around the median. J. Exp. Soc. Psychol. 49, 764-766. doi:10.1016/j.jesp.2013.03.013

NASA/ICESat [WWW Document], n.d. URL http://icesat.gsfc.nasa.gov/

Satgé, F., Bonnet, M.P., Timouk, F., Calmant, S., Pillco, R., Molina, J., Lavado-Casimiro, W., Arsen, A., Crétaux, J.F., Garnier, J., 2015. Accuracy assessment of SRTM v4 and ASTER GDEM v2 over the Altiplano watershed using ICESat/GLAS data. Int. J. Remote Sens. 36, 465488. doi:10.1080/01431161.2014.999166 